\title{
Selecting Aquifer Wells for Planned Gyroscopic Logging
}

\author{
Michael J. Rohe \\ Gregory W. Studley
}

April 2002

Idaho National Engineering and Environmental Laboratory Bechtel BWXT Idaho, LLC 


\title{
Selecting Aquifer Wells for Planned Gyroscopic Logging
}

\author{
Michael J. Rohe \\ Gregory W. Studley
}

April 2002

\section{Idaho National Engineering and Environmental Laboratory Environmental Restoration Program Idaho Falls, Idaho 83415}

\section{Prepared for the}

U.S. Department of Energy

Assistant Secretary for Environmental Management

Under DOE Idaho Operations Office

Contract DE-AC07-99ID13727 


\section{SUMMARY}

Understanding the configuration of the eastern Snake River Plain aquifer's

water table is made difficult, in part, due to borehole deviation in aquifer wells. A borehole has deviation if it is not vertical or straight. Deviation impairs the analysis of water table elevation measurements because it results in measurements that are greater than the true distance from the top of the well to the water table. Conceptual models of the water table configuration are important to environmental management decision-making at the INEEL; these models are based on measurements of depth to the water table taken from aquifer wells at or near the INEEL. When accurate data on the amount of deviation in any given borehole is acquired, then measurements of depth-to-water can be adjusted to reflect the true depth so more accurate conceptual models can be developed. Collection of additional borehole deviation data with gyroscopic logging is planned for selected wells to further our confidence in the quality of water level measurements.

Selection of wells for the planned logging is based on qualitative and quantitative screening criteria. An existing data set from magnetic deviation logs was useful in establishing these criteria however, are considered less accurate than gyroscopic deviation logs under certain conditions. Population distributions for 128 aquifer wells with magnetic deviation data were used to establish three quantitative screening thresholds. Qualitative criteria consisted of administrative controls, accessibility issues, and drilling methods. Qualitative criteria eliminated all but 116 of the 337 aquifer wells, in the vicinity of the INEEL, that were initially examined in this screening effort. Of these, 72 have associated magnetic deviation data; 44 do not. Twenty-five (25) of the 72 wells with magnetic deviation data have deviation greater than one of the three quantitative screening thresholds. These 25 are recommended for the planned gyroscopic borehole deviation surveying. Nineteen (19) of the 44 wells without magnetic deviation data were selected for the planned gyroscopic logging based on their location relative to facilities, site boundaries, and contaminant transport concerns. In total, 44 aquifer wells ( 25 with magnetic deviation data and 19 without) are recommended for planned gyroscopic logging. 


\section{CONTENTS}

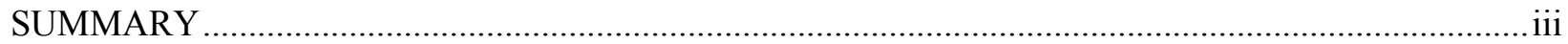

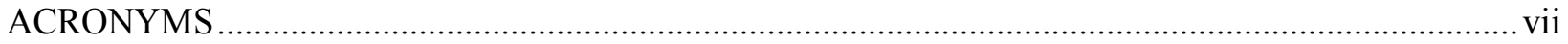

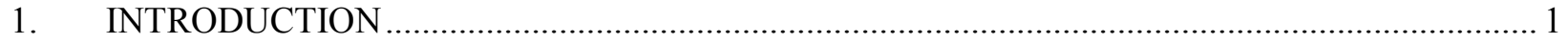

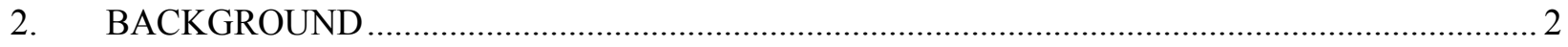

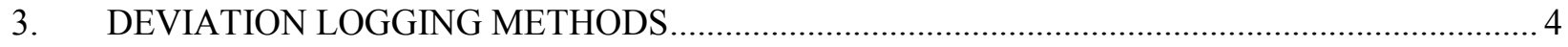

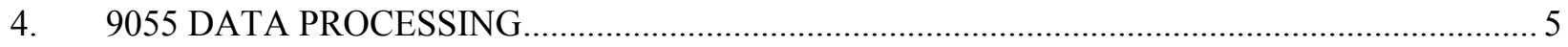

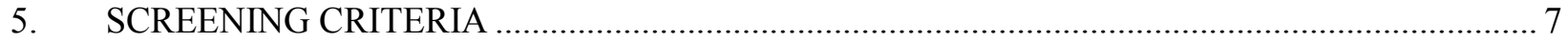

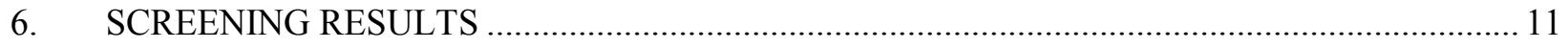

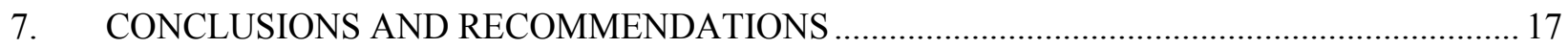

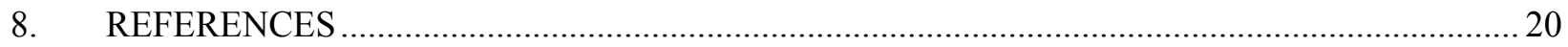

Appendix A—Principal information for 337 aquifer wells initially considered for planned gyroscopic logging.

Appendix B - Century Geophysical Corporation data sheets for 9055 and 9095 tools.

Appendix C - Compu-log plan view diagrams of borehole deviation for wells with magnetic deviation data.

Appendix D_Tables showing derivation of lists of wells recommended for planned gyroscopic logging.

Appendix E — Long-Term Stewardship (LTS) Annual Status Report-2001 Sitewide Digital Gyroscopic and Magnetic Logging of Wells and Boreholes.

\section{FIGURES}

1. Borehole deviation description (from Driscoll, 1987) ........................................................... 2

2. Histograms of magnetic deviation data: a. Average inclination angles for 128 aquifer wells; b. Correction factors for 128 aquifer wells based on average inclination angle and maximum depth-to-water.

3. Flow chart showing qualitative and quantitative screening

4. Location of wells that are high-priority for planned gyroscopic logging following application

of three quantitative screening levels for borehole deviation

5. Location of wells that are high-priority for planned gyroscopic logging based on location, contaminant issues, and casing material 
6. Spatial distribution of wells with existing gyroscopic survey data and wells with magnetic deviation data that pass quantitative screening levels

\section{TABLES}

1. Comparison of correction factors developed from data collected with different logging devices ..... 6

2. Summary statistics for 128 wells with available magnetic deviation data .................................... 7

3. Average inclination angles for different well drilling methods, from 128 INEEL aquifer wells..... 10

4. Aquifer well priority for planned gyroscopic logging based on quantitative screening levels ........ 13

5. Aquifer well priority for planned gyroscopic logging based on location, contaminant issues, and casing material 


\section{ACRONYMS}

bls below land surface

CFA Central Facilities Area

DOE Department of Energy

DQO Data Quality Objectives

INEEL Idaho National Engineering and Environmental Laboratory

RWMC Radioactive Waste Management Complex

TAN Test Area North

USGS United States Geological Survey

WAG Waste Area Group 


\section{Selecting Aquifer Wells for Planned Gyroscopic Logging}

\section{INTRODUCTION}

The Waste Area Group (WAG) 10 of the INEEL Environmental Restoration Department is responsible for the integration of groundwater data from individual WAGs for the purpose of identifying deficiencies. This is part of the Data Quality Objectives (DQO) process that supports the long-term monitoring goals and objectives expected by regulatory agencies for prudent stewardship of this U.S. Department of Energy (DOE) site.

Much of this data is collected directly from the regional aquifer beneath the INEEL. Aquifer wells completed in the eastern Snake River Plain aquifer beneath the INEEL are routinely monitored to better characterize groundwater quality, to study the potential for contaminant migration, and to provide input for the design of remedial activities. Knowledge of the surface of the aquifer, or water table, is used to infer general groundwater flow direction and magnitude, including preferential flowpaths; these, in turn, predominantly influence the location and sampling schedules for new monitoring wells.

Current water table configuration modeling is based on the behavior of water levels observed in aquifer wells. Nearly 200 aquifer wells at or near the INEEL are routinely measured for water levels, some only annually while others are measured more frequently. The measurement process is not without error. Measuring equipment can be unreliable, tapes or cables can stretch or kink, and human error can occur while reading the instruments or transcribing the collected data.

An additional systematic error in water level data can arise if the well was constructed in a manner other than truly vertical or perfectly straight. Deviation impairs the analysis of water table elevation measurements because it results in measurements that are greater than the true distance from the top of the well to the water table. However, the error can be removed if the degree of deviation is known. Procedures and equipment for detecting and assessing borehole deviation are commonplace in the well construction industry.

To enhance the integrity of collected water level data, WAG 10 is scheduled to conduct digital gyroscopic deviation logging of selected aquifer wells based on the criteria presented in this report. To minimize the work scope of the planned logging, wells to be surveyed were selected from an initial set of 337 aquifer wells. This report describes the selection process. The scope of the screening was limited to analyzing available deviation data and the factors contributing to borehole deviation, developing a screening process, and recommending a list of wells which should receive high priority for planned digital gyroscopic logging. 


\section{BACKGROUND}

The INEEL includes approximately 900 square miles of southeastern Idaho desert located above the eastern Snake River Plain aquifer, one of the country's most pristine and abundant water resources. Water in this aquifer generally flows from northeast to southwest as determined by the configuration of the water table which slopes at an average gradient of $12 \mathrm{ft} / \mathrm{mi}$ (Lindholm, 1996). Beneath the INEEL, the water table is approximately $200 \mathrm{ft}$ below land surface (bls) in the northern end of the Site and approximately $600 \mathrm{ft}$ bls along the INEEL's southern boundary. Land surface topography also dips from northeast to southwest but at a more gradual rate.

In 1999, the water table elevation at the northeast INEEL boundary was $4670 \mathrm{ft}$ above mean sea level. Some 50 miles to the southwest, along the southern boundary, the water table elevation was $4430 \mathrm{ft}$. This is an average gradient of $4.8 \mathrm{ft} / \mathrm{mi}$, close to the average $4 \mathrm{ft} / \mathrm{mi}$ reported in other INEEL aquifer studies (Anderson, Kuntz, and Davis, 1999). Such a small hydraulic gradient can be difficult to detect with water levels collected from aquifer wells adjacent to each other. It can also be frustrating to map. Questionable contour maps of the aquifer potentiometric surface have been developed for groundwater modeling or monitoring evaluations in past studies at the INEEL.

The ideal undeviated borehole is both vertical (plumb) and straight (true). In some cases, the reported water table elevation has included error attributed to borehole deviation in aquifer wells (Wylie, 1993). Because the deviated borehole does not follow a straight line or is not vertical, additional measuring line is required to reach the aquifer, giving the false impression of a lower water table at this location. This is illustrated in Figure 1. In this report, inclination refers to the angle measured from vertical that an off-plumb well makes. Inclination azimuth describes the twisting or corkscrewing of an untrue borehole.

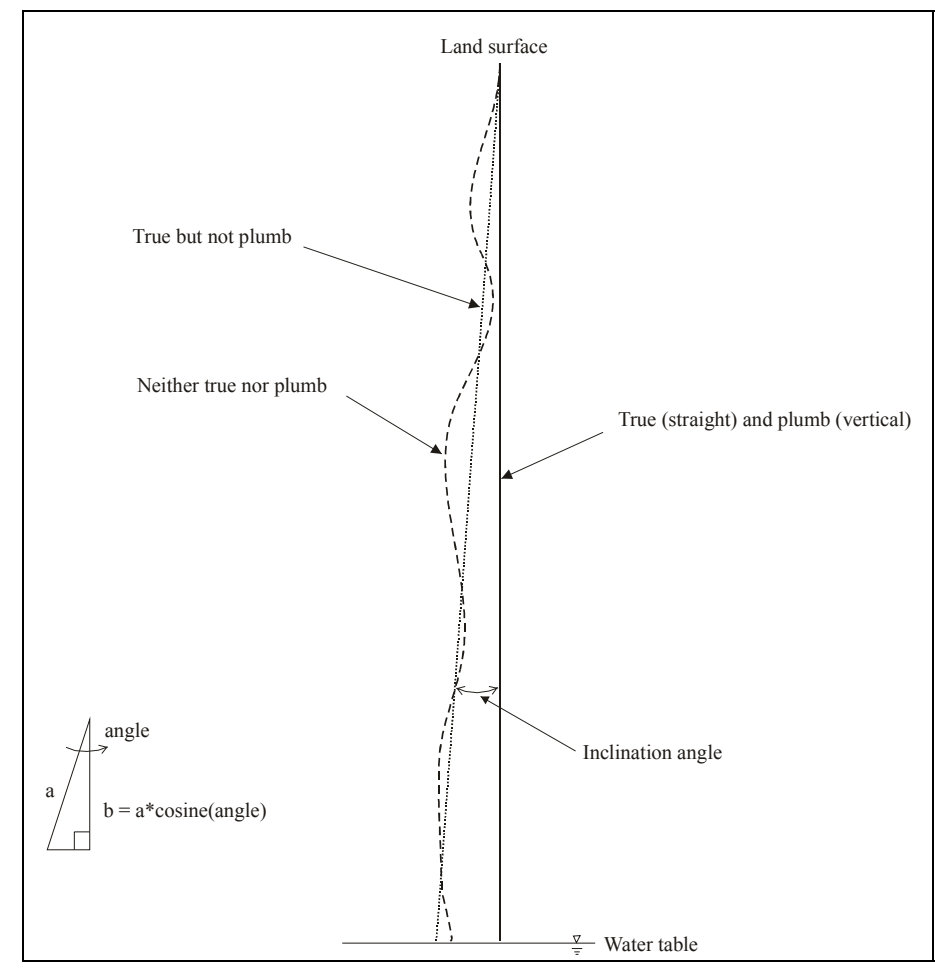

Figure 1. Borehole deviation description (from Driscoll, 1987). 
Previous work identified error, attributed to borehole deviation, in water level measurements collected from aquifer monitoring wells located near the Central Facilities Area (CFA) landfills I and II (Wylie, 1993; Wylie and Hubbell, 1993). In that effort, photo gyroscopic equipment was used to log wells and the results provided a means of quantifying the degree of deviation. Readings of borehole inclination and inclination azimuth were recorded at discrete depths in each well, regression equations were fitted to the readings, and linear expressions were developed from which a unique correction factor can be found for any measured depth. In another study (Wylie, 1996), magnetic deviation data collected during borehole neutron-logging were similarly processed to develop quadratic-equation-based correction formulae.

There are over 340 aquifer wells at or near the INEEL. Principal details for 337 of these are provided in Appendix A. Almost all of these wells have associated water level information useful for developing aquifer configuration conceptual models. Gyroscopic logging is planned for a selected subset of these wells. Both qualitative and quantitative criteria were used to screen wells to find candidate wells for the planned gyroscopic logging. These criteria are described in Section 5. 


\section{DEVIATION LOGGING METHODS}

The simplest deviation logging device consists of a single-shot device with a circular card mounted on a magnetic compass that is passed through drill pipe to record the borehole inclination and inclination azimuth at the hole bottom.

An improvement on this method, the magnetic multi-shot camera, measures multiple readings of direction and inclination at specific depths. A similar method using photo gyroscopic equipment was used by Strata Data Inc. at the INEEL in the 1993 CFA study (Wylie, 1993). The Strata Data equipment included a Humphrey gyroscope, Welnav inclinometer, and a multi-shot camera. The two inclination devices, a low-angle and a high-angle unit, were reported with ranges of 0 to $12 \pm 0.125$ degrees and 0 to 34 degrees \pm 0.25 degrees, respectively (Wylie, 1993). The inclination azimuth reading was reported to have an accuracy of \pm 0.5 degrees. Twenty-six (26) aquifer wells at the INEEL were logged with this equipment.

The United States Geological Survey (USGS) routinely logs boreholes with a logging tool that contains magnetic deviation components. The tool is the multi-parameter model 9055 , manufactured by the Century Geophysical Corporation of Tulsa, OK, which contains a 3-axis magnetometer for inclination azimuth and a 2-axis inclinometer for inclination angle. The tool reads inclinations from vertical ranging from 0 to 45 degrees with \pm 0.5 -degree accuracy and has an inclination azimuth range of 0 to $360 \pm 2$ degrees (Peterson, undated). Although its main function, as used by the USGS, is neutron measurement of formation moisture content, it also provides useful magnetic borehole deviation data. Additional information on this tool is presented in Appendix B. In all, about 130 INEEL aquifer wells have been logged with the 9055 tool during which magnetic deviation data were collected.

Yet another method of borehole deviation logging uses the Century Geophysical digital gyroscopic tool, model 9095, used by the USGS at the INEEL. This tool is fully dedicated to borehole deviation detection. It is intended for logging within steel casings or open holes and can be used where magnetic rocks occur. The digital solid state design incorporates a continuous-reading Humphrey gyroscope that has a range and accuracy of 0 to 45 degrees from vertical \pm 0.5 degree and has an azimuth range of 0 to $360 \pm 2$ degree (Century Geophysical Corp.). Additional information for this tool, is presented in Appendix B. Fourteen (14) aquifer wells at or near the INEEL have been logged using this tool. More gyroscopic logging in aquifer wells suspected of being deviated is scheduled for summer 2001 .

Digital gyroscopic deviation logging (using the 9095) is time-consuming because the tool requires long startup and shutdown times (Peterson, undated). Magnetic deviation data, on the other hand, has been routinely collected when the USGS logs a well using the 9055 tool in its neutron moisture-detection capacity. Although the 9055 tool has an efficient rapid retrieval and real time application, the borehole deviation portion of this tool is not intended for use in wells with metal casings or in formations containing naturally magnetic material (Helm-Clark, 2001). Still, deviation data collected with this tool from 128 aquifer wells were available for this study. 


\section{9055 DATA PROCESSING}

Electronic copies of 1,585 logging files, including 500 magnetic deviation files, were obtained from the USGS. Many of these logs were not useful for this study because they were obtained from the same borehole or were from vadose zone wells. Of the 337 aquifer wells initially examined for screening, 130 were found to have associated magnetic deviation data files. Of these, 128 were useful for establishing screening criteria and screening aquifer wells.

Century Geophysical Corporation software (Log v.3.43, Display v.3.64), which includes a proprietary algorithm to calculate true depths from readings of inclination angle and bearing (azimuth), was used to process these 128 magnetic deviation files. The output includes true depth, cable (measured) depth, inclination angle, bearing (azimuth), and plan view plots showing the downhole trace relative to plumb. (The plan view plots for 128 aquifer wells can be found in Appendix C.) The output was included in a database of well information and corrected depths. This database was queried to find the difference between true and measured depths for each well. From these, correction factors were determined for the expected range of depths-to-water at each well.

In a borehole, deviation adds length to the distance that a measuring device must travel to reach a reference depth such as the aquifer water table. By subtracting the correction factor from the measured depth, the depth is reduced to reflect the actual vertical distance ("true depth"). This correction factor is obtained from the formula:

True Vertical Depth $=$ Measured Depth - Correction Factor

Correction Factor $=$ Measured Depth - True Vertical Depth

If a borehole is somehow drilled straight and plumb after an initial jog or dogleg, the required correction factor may be a constant. Otherwise, the correction factor increases with depth. Therefore, the worst case correction factor is best represented by the difference between true and measured depths at the historical maximum water table depth at each well.

The correction factors obtained from the Century Geophysical software processing of magnetic deviation data resemble the results obtained with other deviation data collection devices (i.e., photo or digital gyroscope devices). Correction factors for wells that were logged with the 9055 neutron tool and also with either the Strata Data photo gyroscopic device or the 9095 digital gyroscopic tool are presented in Table 1.

The results in Table 1 show an acceptable level of agreement between the 9055-derived corrections, calculated using the Century Geophysical software algorithm, and corrections obtained with other methods. Yet, in cases of large deviation, the 9055 tool underestimates the deviation. This is likely due to the lack of magnetometer control in metal-cased wells. At low levels of deviation, the 9055 and 9095 tools produce similar ranges of correction factors. At low inclination angles, both tools can hang plumb and yield readings that indicate a true and plumb borehole. At higher levels of deviation, the corkscrewing becomes significant and an accurate reading of inclination azimuth becomes important. The 9095 can provide a higher level of inclination azimuth accuracy because it is designed for use in metalcased wells. The lack of azimuth control with the 9055 in metal-cased wells is evident from the incredible plan view plots in Appendix C, though some of these are probably the result of using the tool without casing centralizers. 
Table 1. Comparison of correction factors developed from data collected with different logging devices.

\begin{tabular}{lccc}
\hline \multicolumn{1}{c}{ Well Name } & $\begin{array}{c}\text { 9055 Data Processed with } \\
\text { Century Software Algorithm (ft) }\end{array}$ & $\begin{array}{c}\text { Digital Gyroscope } \\
\text { (ft) }\end{array}$ & $\begin{array}{c}\text { StrataData } \\
\text { Photo Gyroscope } \\
\text { (ft) }\end{array}$ \\
\hline ANL-OBS-A-001 & 0.04 & 0.04 & - \\
TANT-MON-A-008 & 0.08 & 0.57 & - \\
TANT-MON-A-009 & 0.04 & 0.03 & - \\
TANT-MON-A-011 & 0.00 & 0.00 & 5.36 \\
LF2-09 & 4.73 & 6.49 & 0.12 \\
LF3-09 & 0.11 & - & 0.09 \\
LF2-12 & 0.09 & - & 0.03 \\
LF3-11 & 0.03 & - & 0.01 \\
LF3-10 & 0.02 & 5.87 & 5.64 \\
USGS-113 & 4.84 & - & 0.21 \\
USGS-116 & 0.16 & 0.17 & - \\
USGS-118 & 0.15 & 1.73 & - \\
USGS-121 & 1.51 & 0.42 & - \\
USGS-126b & 0.46 & & \\
\hline a. photo gyroscope data from Wylie (1993). & & & \\
\hline
\end{tabular}

Due to the questionable azimuth data, the USGS uses a different method for calculating the correction factor from magnetic deviation data. Their method is to ignore the inclination azimuth data and to rely only on the average inclination angle from land surface to water table. They use the cosine of this average angle and multiply it by the measured depth to obtain true depth. The correction factor formula then becomes:

Correction Factor $=$ Measured Depth $-[$ Measured Depth $\times$ Cosine (average inclination angle) $]$

The above formula was used in conjunction with 128 wells that have existing 9055 deviation data. The database of Century Geophysical software-processed results was used to find well-specific average inclination angles and to calculate correction factors with these angles at maximum depth-to-water.

It should be noted that these calculated correction factors are used in this report only to screen wells for planned deviation logging. They are not intended to correct existing or future sets of water level data. These factors have not been developed with the same rigor as the linear- or quadratic-equation-based corrections developed in earlier deviation analyses (Wylie, 1993; Wylie and Hubbell, 1993; Wylie, 1996). 


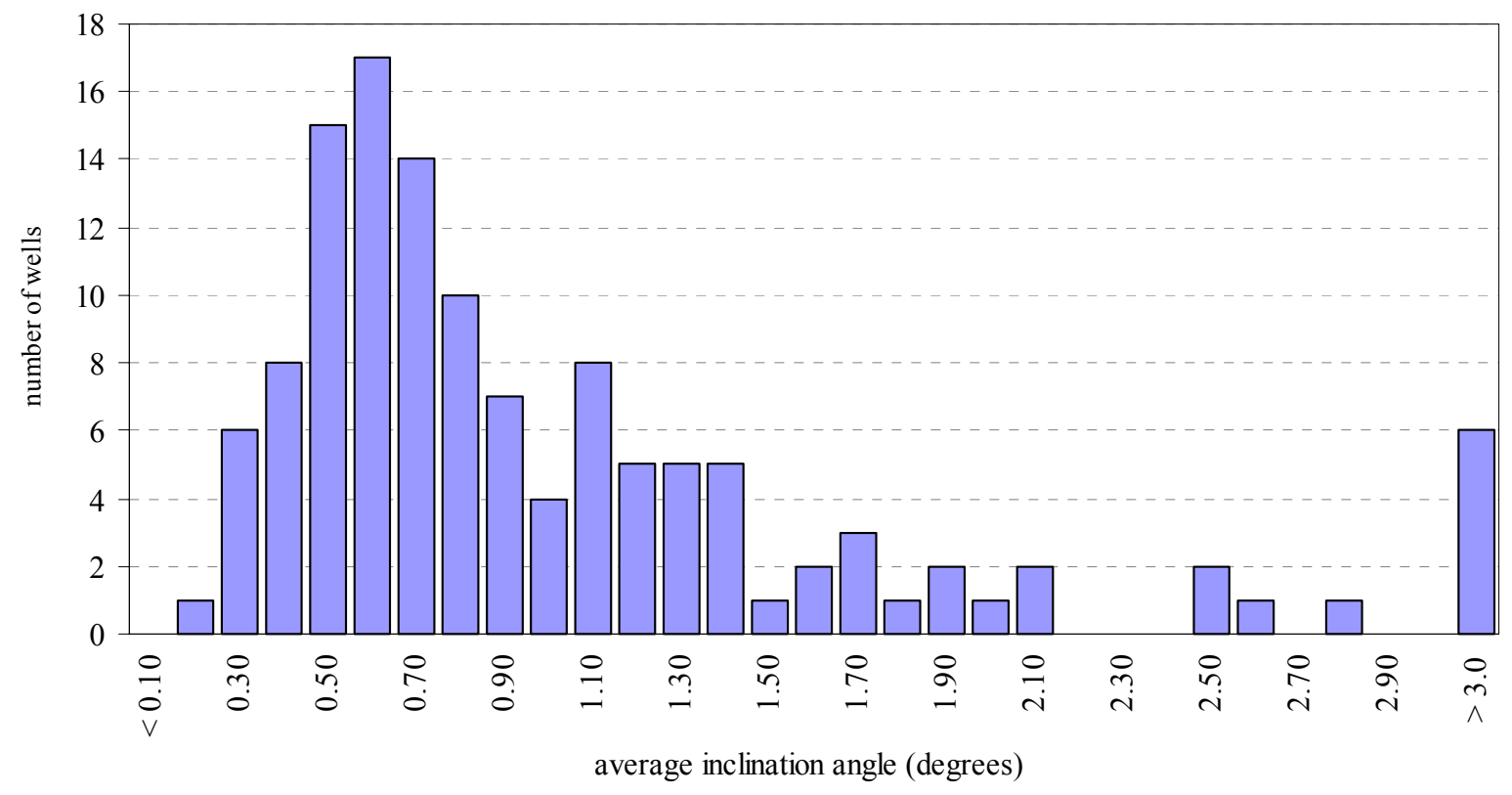

a.

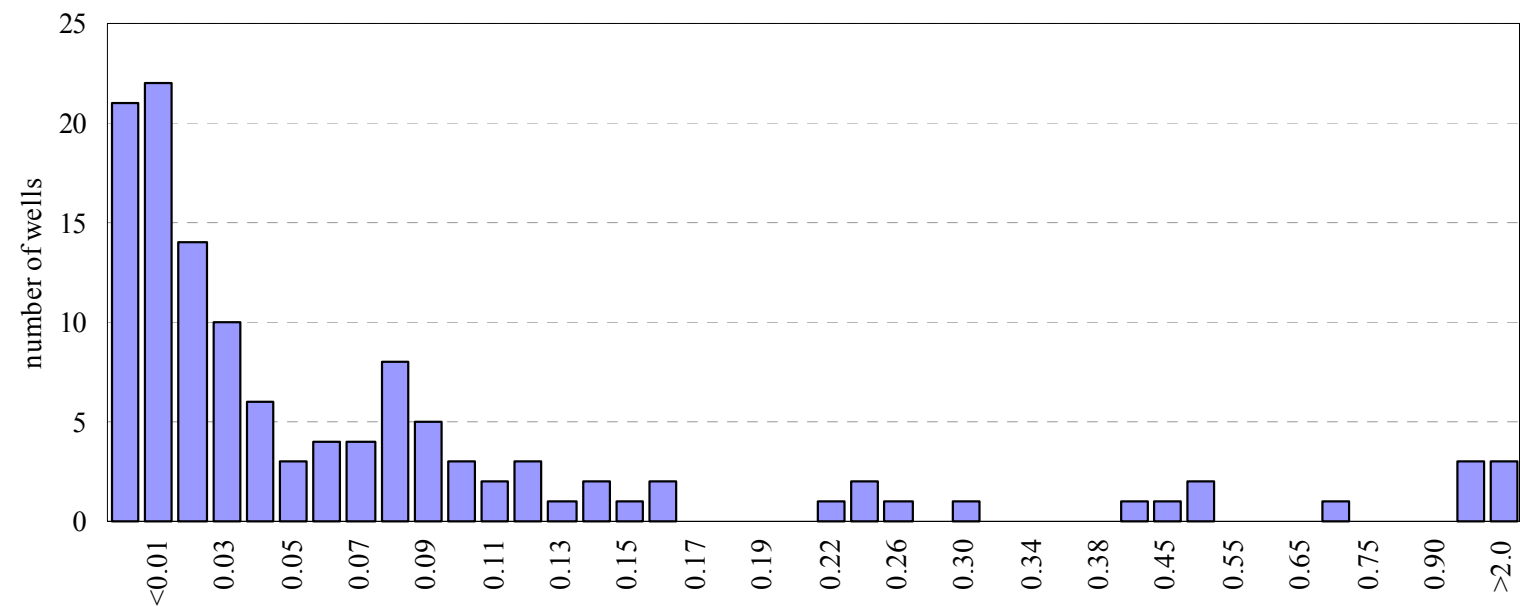

Correction factor for true versus measured depth based on magnetic deviation inclination angle ( $\mathrm{ft}$ )

b.

Figure 2. Histograms of magnetic deviation data: a. Average inclination angles for 128 aquifer wells; $b$. Correction factors for 128 aquifer wells based on average inclination angle and maximum depth-to-water. 
The 9055 tool measures inclination within a 0.5 -degree tolerance. To account for this accuracy limitation in this analysis, 0.5 degrees is added to the average inclination angle for each well. Therefore, the sum represents the maximum possible average inclination for each well, based on 9055-derived data. To determine the correction factor for each well, the cosine of the sum of 0.5 degrees and the average inclination angle is multiplied by the measured depth; this product is then subtracted from the measured depth. The new correction factor formula is:

Correction Factor $=$ Measured Depth $-[$ Measured Depth $\times$ Cosine $($ average inclination angle +0.5$)]$

Calculated correction factors for each well using this formula are listed in Tables D-6A and D-6B of Appendix D. In this analysis, the 0.3 -ft correction factor is adopted as the highest quantitative screening criterion. Wells with existing magnetic deviation data that are found to have correction factors greater than $0.3 \mathrm{ft}$ are given highest priority for planned gyroscopic deviation logging. The two other quantitative screening criteria used to assign medium and low priorities for planned gyroscopic logging are a $0.2-\mathrm{ft}$ and $0.1-\mathrm{ft}$ correction factor, respectively. The 0.2 -ft correction factor criterion represents the average of correction factors obtained for 128 aquifer wells using either the Century Geophysical software or equation (3), with measured depths and average inclination angles. The 0.1 - $\mathrm{ft}$ criterion is close to the group correction factor (0.08) obtained from the average depth-to-water (441 ft bls) and the average inclination angle (1.09 degrees) found from the set of 128 wells with magnetic deviation data.

Initially, a set of qualitative screening criteria was used to minimize the number of wells recommended for gyroscopic logging. These qualitative criteria include accessibility (abandoned wells, private offsite wells, and turbine-equipped production wells were screened out), administrative control (USGS-owned wells were screened out), and inferences between borehole deviation and drilling methods. Wells with existing gyroscopic deviation data, whether collected with the Strata Data device or the Century Geophysical 9095 tool, do not need to be logged with a gyroscopic tool again and therefore are excluded from further consideration.

Inferences, between borehole deviation and drilling methods, are based on the observation that drilling methods for construction of aquifer wells at or near the INEEL appear to affect borehole deviation. Table 3 presents the summarized inclination angle results for different drilling types used at the INEEL. The oldest INEEL aquifer wells, constructed between 1949 and 1963, were drilled using the cable-tool percussion method. This method is based on the repeated lifting and dropping of a heavy string of drilling tools that, due to cable twisting, rotate upon impact at the bottom of the hole allowing the bit to crush and cut through rock. While the force of gravity tends to make the drill bit cut a vertical hole, the varying hardness of differing subsurface materials can deflect the bit from a truly vertical course (Driscoll, 1987). However, 26 INEEL cable-tool drilled aquifer wells yielded an average inclination angle of only 0.88 degrees.

Air-rotary drilling uses compressed air to blow cuttings out the borehole in the annular space between the drill string and the borehole wall. This method typically uses a conventional rotating bit with pressure applied through the drill string to advance the bit. Too much pressure applied at the top of the drill stem will bend the drill pipe, causing the bit to cut off-center and produce a highly-deviated borehole (Driscoll, 1987). Analysis of magnetic deviation data from 35 aquifer wells, identified as being drilled with the conventional air-rotary and tri-cone bit method, yielded an average inclination angle of 1.80 degrees. This method was popular in the 1980s when the CFA landfill wells and other wells were drilled, and they have major borehole deviation. Wylie (1993) used whisker-and-box plots to demonstrate that the air-rotary method produced significantly more borehole deviation than the cable-tool method. 
Table 3. Average inclination angles for different well drilling methods, from 128 INEEL aquifer wells.

\begin{tabular}{|c|c|c|}
\hline Drill Method & $\begin{array}{c}\text { Average of Inclination Angles } \\
\left(^{(\text {degrees })^{\mathrm{a}}}\right.\end{array}$ & Number of Wells \\
\hline Air-rotary & 1.80 & 35 \\
\hline Coring & 1.24 & 10 \\
\hline Cable tool & 0.88 & 26 \\
\hline Downhole hammer & 0.82 & 33 \\
\hline Reverse circulation & 0.64 & 23 \\
\hline Unknown $^{\mathrm{b}}$ & 0.63 & 1 \\
\hline
\end{tabular}

Several INEEL aquifer wells were core-drilled in support of geologic analyses of the vadose zone and aquifer matrix. The coring method uses a wire-line retrievable core-sampling barrel, which is lowered down the inside of the drill string and removed to collect the core sample. The set of 10 cored INEEL aquifer wells with magnetic deviation data produced the second highest average inclination of 1.24 degrees.

The downhole hammer method uses a pneumatic-percussion hammer and rotating bit. Like cabletool drilling, the hammering allows the bit to crush through materials of contrasting hardness with little or no drift and produces a fairly straight and plumb hole. This is evidenced by the average inclination angle of 0.82 degrees for the set of 33 INEEL aquifer wells drilled with this method.

Reverse-circulation removes cuttings through the outer annular space between a double-walled drill stem and can be used with various bit types. The list of 23 INEEL aquifer wells constructed with reversecirculation does not include any information regarding the type of bit used with this method, i.e., whether downhole hammer or tri-cone rotary bits were used. However, the low inclination angle average of 0.64 degrees for this set of wells suggests that a hammer bit was probably used.

The magnetic deviation data summarized in Table 3 suggest that drilling methods do affect borehole deviation. It appears that wells constructed with the air-rotary method are more likely to be deviated that those constructed with the cable-tool method, as identified in previous studies (Wylie, 1993). This is useful for screening out wells constructed with a certain drilling method (i.e., cable-tool or downhole hammer) but for which no screening deviation data exists. The consistency of these data also suggests that the 9055-derived inclination data can be used as a screening-criteria assessment of borehole deviation. 


\section{SCREENING RESULTS}

Prior to assessing borehole deviation in wells with available 9055 magnetic deviation data, qualitative screening criteria were used to pare the list of 337 aquifer wells down to a more manageable list of 116 wells. A logic flowchart showing these qualitative criteria is presented in Figure 3 . These criteria and the number of wells eliminated from further consideration for gyroscopic logging are:

- $\quad$ Existing gyroscopic deviation data. Wells that have been previously logged with either photo or digital gyroscopic deviation tools are considered finished with regard to gyroscopic logging needs. Twelve (12) INEEL aquifer wells have been surveyed with the digital gyroscope by the USGS, and 24 have been logged by the Strata Data Corporation of Wyoming using the photo gyroscope device. Two additional wells were logged with both methods. This step eliminated 38 aquifer wells, leaving 299.

- USGS-controlled wells. All aquifer wells at or near the INEEL that are under USGS administrative control were removed from further gyroscopic logging consideration. This eliminated 88 of the wells, leaving 211.

- Inaccessible wells. All aquifer wells deemed inaccessible (i.e., abandoned wells, private offsite wells, production wells equipped with turbine pumps) were removed from further gyroscopic logging consideration. This eliminated 45 aquifer wells, leaving 166.

- $\quad$ Drilling method. All aquifer wells constructed with the historically-plumb cable-tool drilling method were eliminated from further screening. This eliminated an additional 50 aquifer wells, leaving 116.

Of the 116 wells remaining after initial qualitative screening, 72 have 9055 logging magnetic deviation data while 44 are without. The 72 wells with available magnetic deviation data were then screened using correction factor criteria, derived from maximum water depths and average inclination angles, with quantitative screening criteria of $0.3,0.2$, and $0.1 \mathrm{ft}$. Table 4 presents the 25 wells that failed at least the lowest criteria. The location of these wells and their relative priority are shown in Figure 4. This includes 15 wells that fail the $0.1-\mathrm{ft}$ screening criterion, 8 wells that fail the $0.2-\mathrm{ft}$ criterion, and 2 wells that fail the $0.3-\mathrm{ft}$ criterion.

The 44 remaining wells, which have no previous magnetic deviation data and were not screened out with qualitative criteria, were ranked for planned gyroscopic logging based on their location relative to facilities and areas of contaminant transport concern. Nineteen (19) wells are considered high-priority with regard to gyroscopic logging; 25 are now considered non-priority.

Wells outside the boundaries of WAG-specific facilities are considered to be within WAG 10 administrative-control domain; these are given a higher priority since they are unlikely to be logged for deviation by any other WAG. Wells downgradient of individual facilities are the most important wells with regard to regulatory groundwater standards compliance and therefore receive a higher ranking. The monitoring wells near the southern INEEL boundaries are the last line of monitoring before groundwater in the eastern Snake River Plain aquifer leaves the vicinity of the INEEL; as a result, these wells are given a higher priority. Deeper wells are also a higher priority because they are more sensitive to inclination angle; i.e., a slight inclination will cause their required correction to be greater than shallower wells with the same amount of inclination. High priority wells that have no existing deviation data are listed in Table 5 and are shown relative to INEEL facilities and site boundaries in Figure 5. Appendix D contains tables delineating the screening process that produced Tables 4 and 5 . 


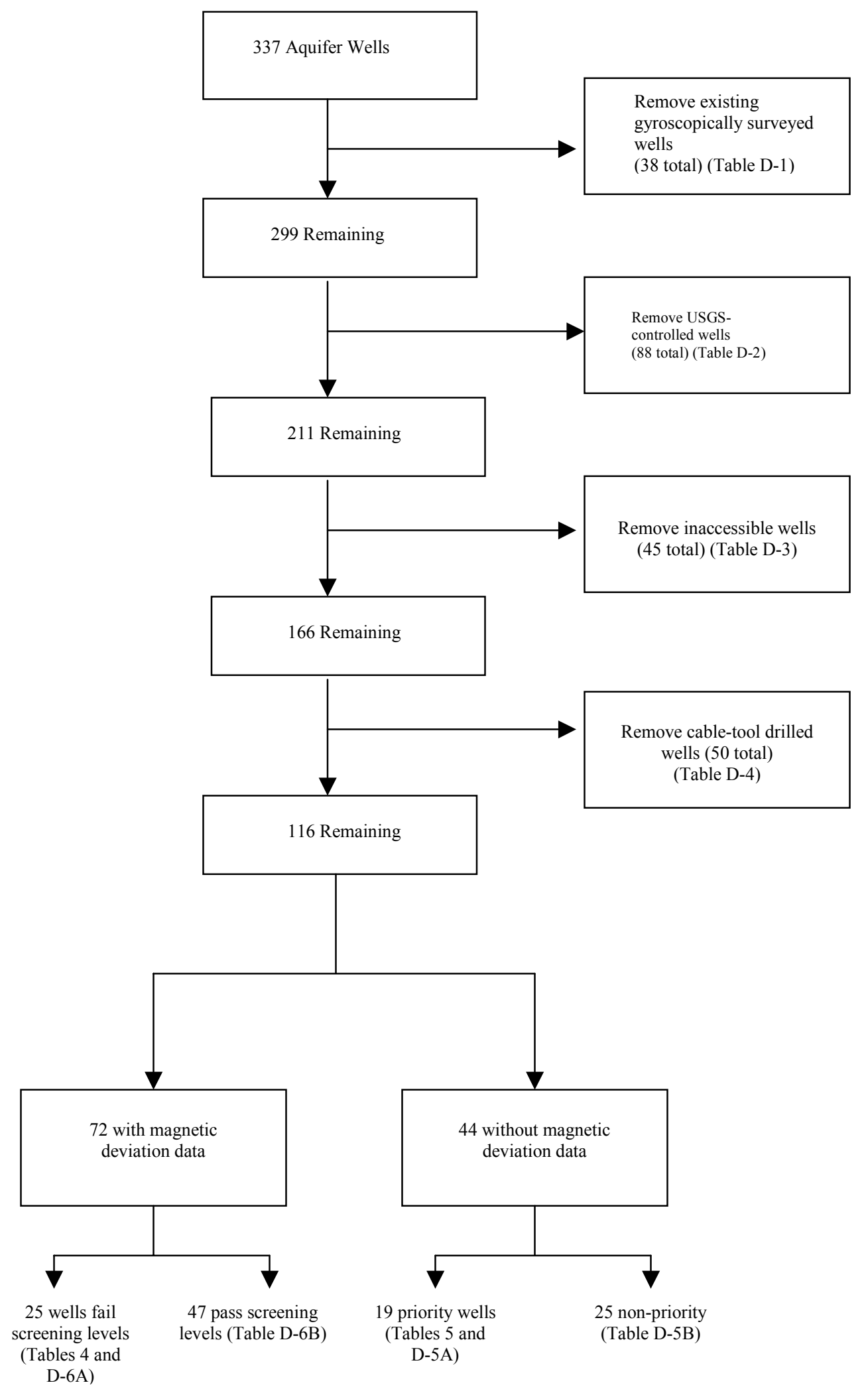

Figure 3. Flow chart showing qualitative and quantitative screening. 
Table 4. Aquifer well priority for planned gyroscopic logging based on quantitative screening levels.

\begin{tabular}{|c|c|c|c|c|c|c|c|}
\hline Priority & Well ID & Well Name & Facility & $\begin{array}{l}\text { Drilling } \\
\text { Method }\end{array}$ & $\begin{array}{l}\text { Maximum } \\
\text { Depth-to- } \\
\text { Water } \\
\text { (ft) }\end{array}$ & $\begin{array}{l}\text { Average } \\
\text { Inclination } \\
\text { Angle } \\
\text { (degrees) }\end{array}$ & $\begin{array}{l}\text { Correction } \\
\text { Factor } \\
(\mathrm{ft})^{\mathrm{a}}\end{array}$ \\
\hline high & 767 & M4D & RWMC & Hammer & 599 & 1.85 & 0.50 \\
\hline high & 1003 & ARA-MON-A-001 & ARA & Hammer & 596 & 1.66 & 0.42 \\
\hline medium & 765 & M1SA & RWMC & Hammer & 596 & 1.14 & 0.24 \\
\hline medium & 96 & Corehole 1 & south Site & Corehole & 938 & 0.81 & 0.24 \\
\hline medium & 906 & RWMC-MON-A-013 & RWMC & Hammer & 641 & 1.05 & 0.24 \\
\hline medium & 769 & M7S & RWMC & Hammer & 580 & 1.11 & 0.23 \\
\hline medium & 797 & TAN-23A & TSF & Air-rotary & 211 & 2.13 & 0.22 \\
\hline medium & 766 & M3S & RWMC & Hammer & 592 & 1.01 & 0.21 \\
\hline medium & 1305 & STF-MON-A-003 & STF/OMRE & Hammer & 499 & 1.14 & 0.20 \\
\hline medium & 790 & TAN-18 & TSF & Air-rotary & 226 & 1.90 & 0.20 \\
\hline low & 1306 & STF-MON-A-004 & STF/OMRE & Hammer & 506 & 1.08 & 0.19 \\
\hline low & 968 & ANL-MON-A-012 & ANL & $\mathrm{NF}^{\mathrm{b}}$ & 648 & 0.88 & 0.19 \\
\hline low & 1092 & ICPP-MON-A-022 & ICPP & $\begin{array}{l}\text { Reverse- } \\
\text { circulation }\end{array}$ & 453 & 1.09 & 0.17 \\
\hline low & 1076 & ARA-COR-A-005 & ARA & $\begin{array}{l}\text { Rotary } \\
\text { cored }\end{array}$ & 597 & 0.88 & 0.17 \\
\hline low & 1080 & NRF-MON-A-009 & NRF & Hammer & 381 & 1.22 & 0.17 \\
\hline low & 1095 & PBF-MON-A-005 & PBF & Hammer & 512 & 0.92 & 0.16 \\
\hline low & 1008 & TANT-MON-A-028 & TAN-TSF & Air-Rotary & 207 & 1.66 & 0.15 \\
\hline low & 1132 & RWMC-MON-A-66 & RWMC & Hammer & 601 & 0.77 & 0.15 \\
\hline low & 1101 & TANT-MON-A-005 & TAN-TSF & $\begin{array}{l}\text { Reverse- } \\
\text { circulation }\end{array}$ & 207 & 1.64 & 0.14 \\
\hline low & 1006 & ARA-MON-A-03A & ARA & Hammer & 608 & 0.65 & 0.12 \\
\hline low & 1314 & TANT-MON-A-047 & TAN & Air-Rotary & 215 & 1.33 & 0.11 \\
\hline low & 1004 & ARA-MON-A-002 & ARA & Hammer & 594 & 0.59 & 0.11 \\
\hline low & 1117 & TANT-MON-A-024 & TAN-TSF & $\begin{array}{l}\text { Reverse- } \\
\text { circulation }\end{array}$ & 203 & 1.31 & 0.10 \\
\hline low & 1087 & PBF-MON-A-003 & PBF & Hammer & 521 & 0.62 & 0.10 \\
\hline low & 1007 & ARA-MON-A-004 & ARA & Hammer & 617 & 0.52 & 0.10 \\
\hline
\end{tabular}




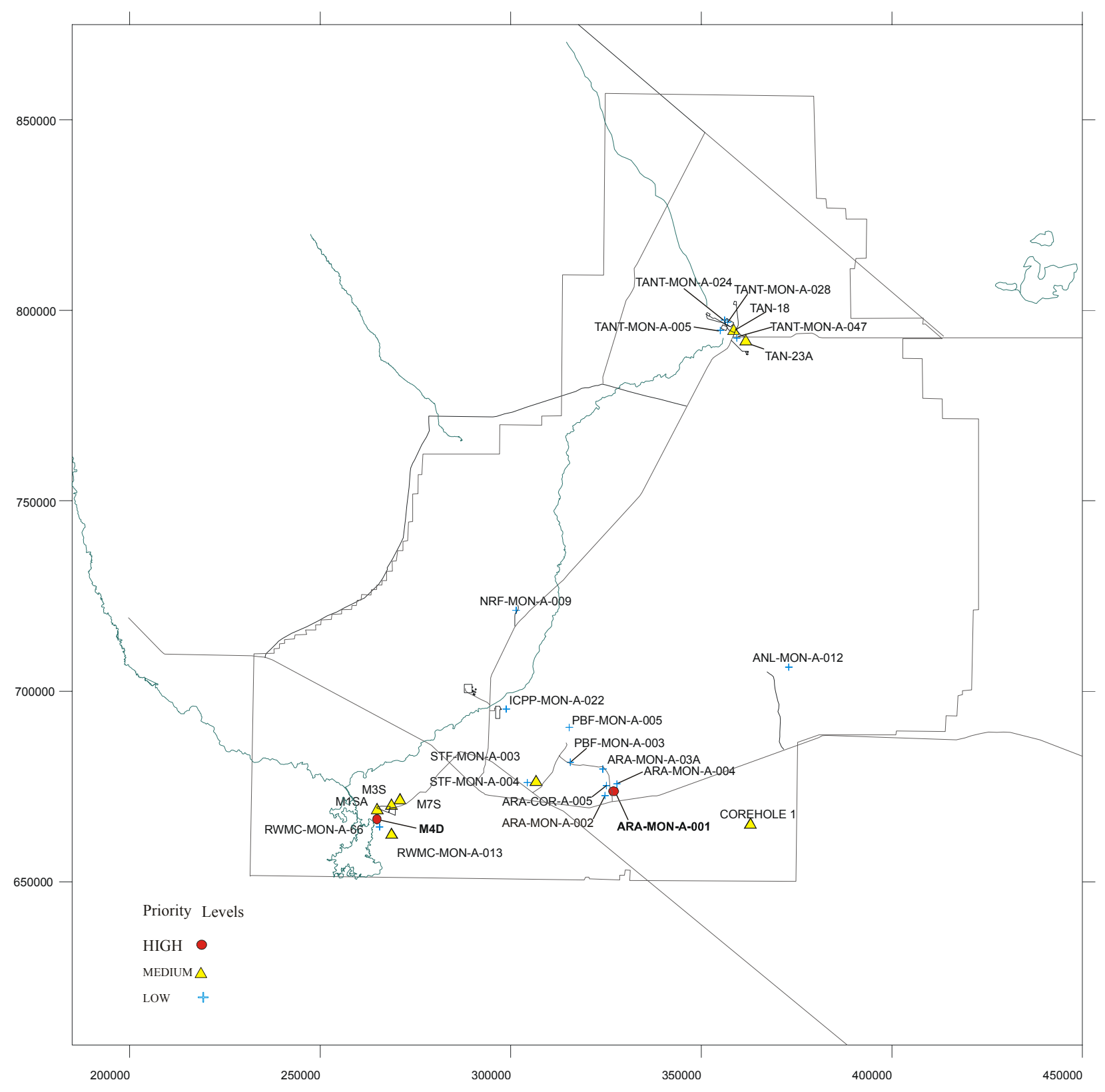

Figure 4. Location of wells that are high-priority for planned gyroscopic logging following application of three quantitative screening levels for borehole deviation. 
Table 5. Aquifer well priority for planned gyroscopic logging based on location, contaminant issues, and casing material.

\begin{tabular}{|c|c|c|c|c|c|c|}
\hline Priority & Well ID & Well Name & Facility & $\begin{array}{l}\text { Drilling } \\
\text { Method }\end{array}$ & $\begin{array}{l}\text { Casing Summary } \\
\text { (top-bottom, ft) }\end{array}$ & $\begin{array}{c}\text { Maximum } \\
\text { Depth-to-Water } \\
(\mathrm{ft})\end{array}$ \\
\hline High & 1340 & TANT-MON-A-054 & TAN & Hammer & carbon steel & $\mathrm{NF}^{\mathrm{b}}$ \\
\hline High & 1341 & TANT-MON-A-055 & TAN & Hammer & carbon steel & $\mathrm{NF}^{\mathrm{b}}$ \\
\hline High & 1342 & TANT-MON-A-056 & TAN & Hammer & carbon steel & $\mathrm{NF}^{\mathrm{b}}$ \\
\hline High & 1343 & TANT-MON-A-057 & TAN & Hammer & carbon steel & $\mathrm{NF}^{\mathrm{b}}$ \\
\hline High & 1344 & TANT-MON-A-058 & TAN & Hammer & carbon steel & $\mathrm{NF}^{\mathrm{b}}$ \\
\hline High & 97 & Corehole 2A & mid Site & $\mathrm{NF}^{\mathrm{b}}$ & carbon steel & 214 \\
\hline High & 719 & ANL-M11 & ANL & Air-rotary & $\begin{array}{l}\text { carbon steel } \\
\mathrm{NF}^{\mathrm{b}}\end{array}$ & 635 \\
\hline Medium & 1143 & ANL-MON-A-014 & ANL & Hammer & stainless & 637 \\
\hline Medium & 186 & INEL- $^{\text {a }}$ & mid Site & Air-rotary & carbon steel & 309 \\
\hline Medium & 239 & NPR Test & mid Site & Air-rotary & carbon steel & 468 \\
\hline Medium & 101 & СРP-04 & ICPP & $\mathrm{NF}^{\mathrm{b}}$ & carbon steel & 582 \\
\hline Medium & 360 & TRA Disposal & TRA & $\mathrm{NF}^{\mathrm{b}}$ & carbon steel & 469 \\
\hline Medium & 731 & TRA-07 & TRA & Air-rotary & stainless & 476 \\
\hline Low & 163 & GIN-05 & WRRTF & Air-rotary & carbon steel & 213 \\
\hline Low & 595 & Water supply INEL-1 ${ }^{\mathrm{a}}$ & mid Site & Air-rotary & carbon steel & 402 \\
\hline Low & 1351 & ICPP-MON-A-165 & INTEC & Hammer & carbon steel and stainless & $\mathrm{NF}^{\mathrm{b}}$ \\
\hline Low & 1352 & ICPP-MON-A-166 & INTEC & Hammer & carbon steel and stainless & $\mathrm{NF}^{\mathrm{b}}$ \\
\hline Low & 1383 & ICPP-MON-A-167 & INTEC & Hammer & carbon steel and stainless & $\mathrm{NF}^{\mathrm{b}}$ \\
\hline Low & 1186 & ICPP-POT-A-012 & ICPP & $\mathrm{NF}^{\mathrm{b}}$ & $\mathrm{NF}^{\mathrm{b}}$ & 445 \\
\hline
\end{tabular}




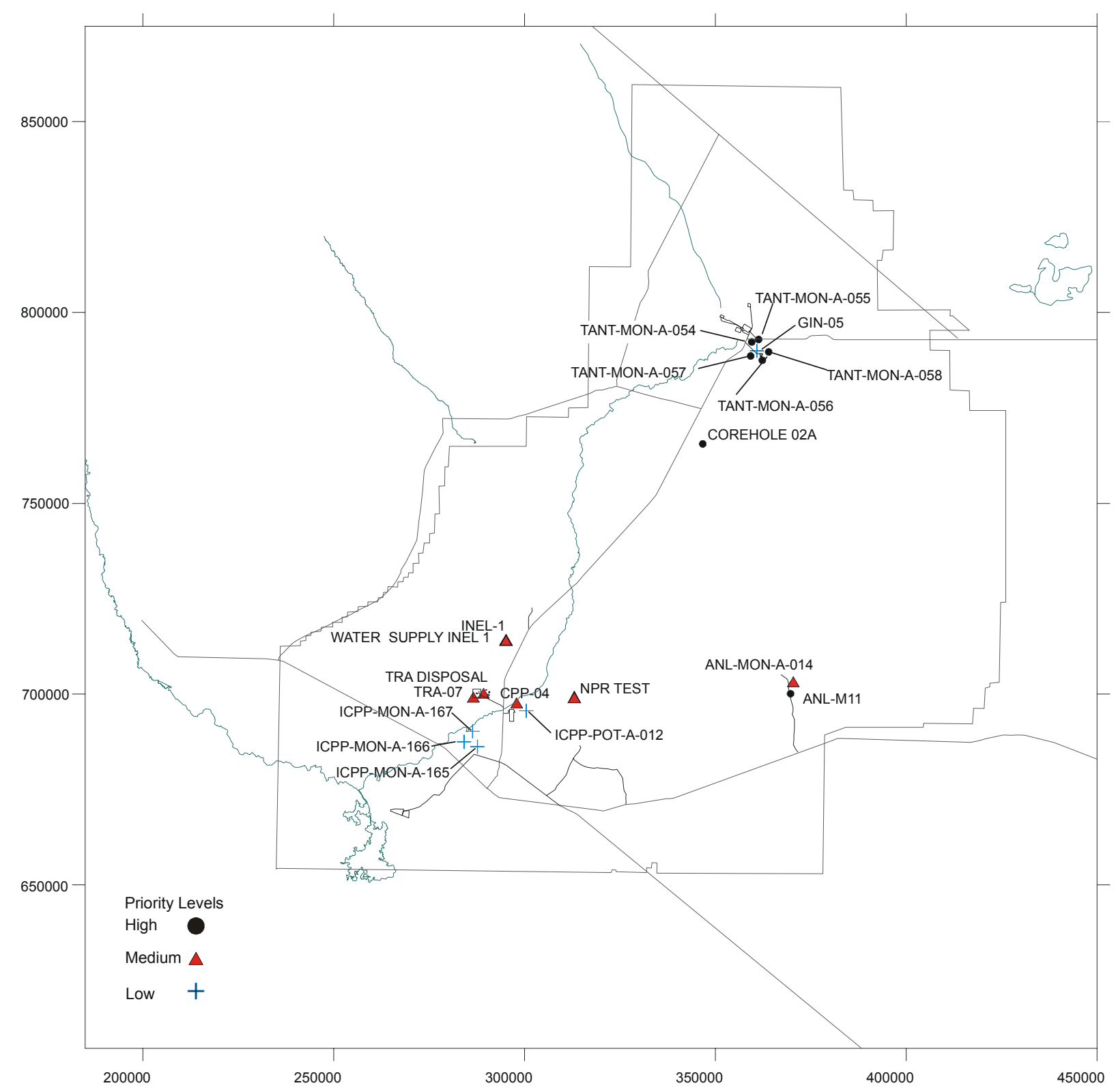

Figure 5. Location of wells that are high-priority for planned gyroscopic logging based on location, contaminant issues, and casing material. 


\section{CONCLUSIONS AND RECOMMENDATIONS}

Scientists at the INEEL maintain information regarding more than 340 aquifer wells located at or near the INEEL. The INEEL lacks an adequate data set of accurate borehole deviation logs for these aquifer wells (only 38 aquifer wells have been logged with either photo or digital gyroscope tools). Past aquifer water table configuration concepts may be inaccurate, in part because of misleading water level information collected from deviated aquifer wells. This study is part of an effort to create a larger database of gyroscopic borehole deviation data on INEEL aquifer wells, which could then be used to better conceptualize aquifer water table configuration.

Logging to assess borehole deviation using the Century Geophysical model 9095 digital gyroscope is planned, because gyroscopic deviation data produces more accurate and reliable results (true versus measured depths) from highly-deviated wells than magnetic logging deviation data. However, the digital gyroscopic logging tool (model 9095), used by the USGS, requires long startup and shutdown times. For that reason, consideration should be given first to logging wells deemed sensitive with regard to borehole deviation. The goal of this study is to prioritize aquifer wells for gyroscopic deviation logging, based on both qualitative and quantitative information.

Qualitative screening criteria were established to initially screen aquifer wells from further consideration for planned gyroscopic logging. These include criteria based on well administrative control, accessibility, drilling methods, and the existence of previous gyroscopic borehole deviation logs. These criteria eliminated 221 of 337 aquifer wells from planned gyroscopic logging.

Quantitative screening criteria, based on magnetic borehole deviation data collected with the Century Geophysical 9055 tool, were then applied to the remaining 116 wells. The quantitative screening criteria were derived from a set of data from 128 wells that have existing magnetic borehole deviation data. In highly-deviated boreholes (i.e., those with approximately 1-ft difference or more between true depth and measured depth at the water table), the magnetic deviation tool underestimates deviation, relative to photo or digital gyroscope tools. Still, data indicates the 9055 tool has an acceptable level of accuracy at lower inclination angles.

In choosing the quantitative screening criteria, it was noted that the USGS uses a $0.3-\mathrm{ft}$ threshold for correction factors (difference between measured and true depths) as determined from magnetic deviation data. Below this threshold, they do not correct water level data. This study adopted the $0.3-\mathrm{ft}$ correction factor as the highest quantitative screening criterion for use with wells that have existing magnetic deviation data. Two other quantitative screening criteria levels were also employed in this study: 0.2 -ft and 0.1 -ft correction factors. These are based on observed population distribution of correction factors generated from borehole magnetic deviation data for the 128 wells.

Of the 116 aquifer wells remaining after the initial qualitative screening, 72 have associated magnetic deviation data; 44 do not. Of the 72 wells with magnetic deviation data, 25 have greater deviation (based on magnetic deviation data) than one of the three quantitative screening levels (correction factors of 0.3-, 0.2-, or 0.1-ft). These are recommended for planned gyroscopic logging. Of the 44 wells that do not have existing magnetic deviation data, 19 were selected for planned gyroscopic logging, based on location relative to facilities, contaminant transport concerns, and site boundaries. In total, 44 aquifer wells ( 25 with magnetic deviation data and 19 without) are recommended for planned gyroscopic logging. These are listed in Tables 4 and 5 in the body of this report and also in Tables D-5A and D-6A of Appendix D.

Of the 337 aquifer wells included in this analysis, 85 are not recommended for digital gyroscopic logging because a) they passed the quantitative screening levels for magnetic deviation logged wells 
(47 wells, Table D-6B), or b) because they already have existing photo or digital gyroscopic survey data (38 wells, Table D-1). The wells presented in Figure 6 which have acceptable magnetic deviation results are limited to INEEL-administered wells; however, the set of wells with gyroscopic survey data include both INEEL-administered and USGS-controlled wells. Appendix E of this report is reserved for revisions containing newly processed magnetic deviation data and acquired gyroscopic survey data. 


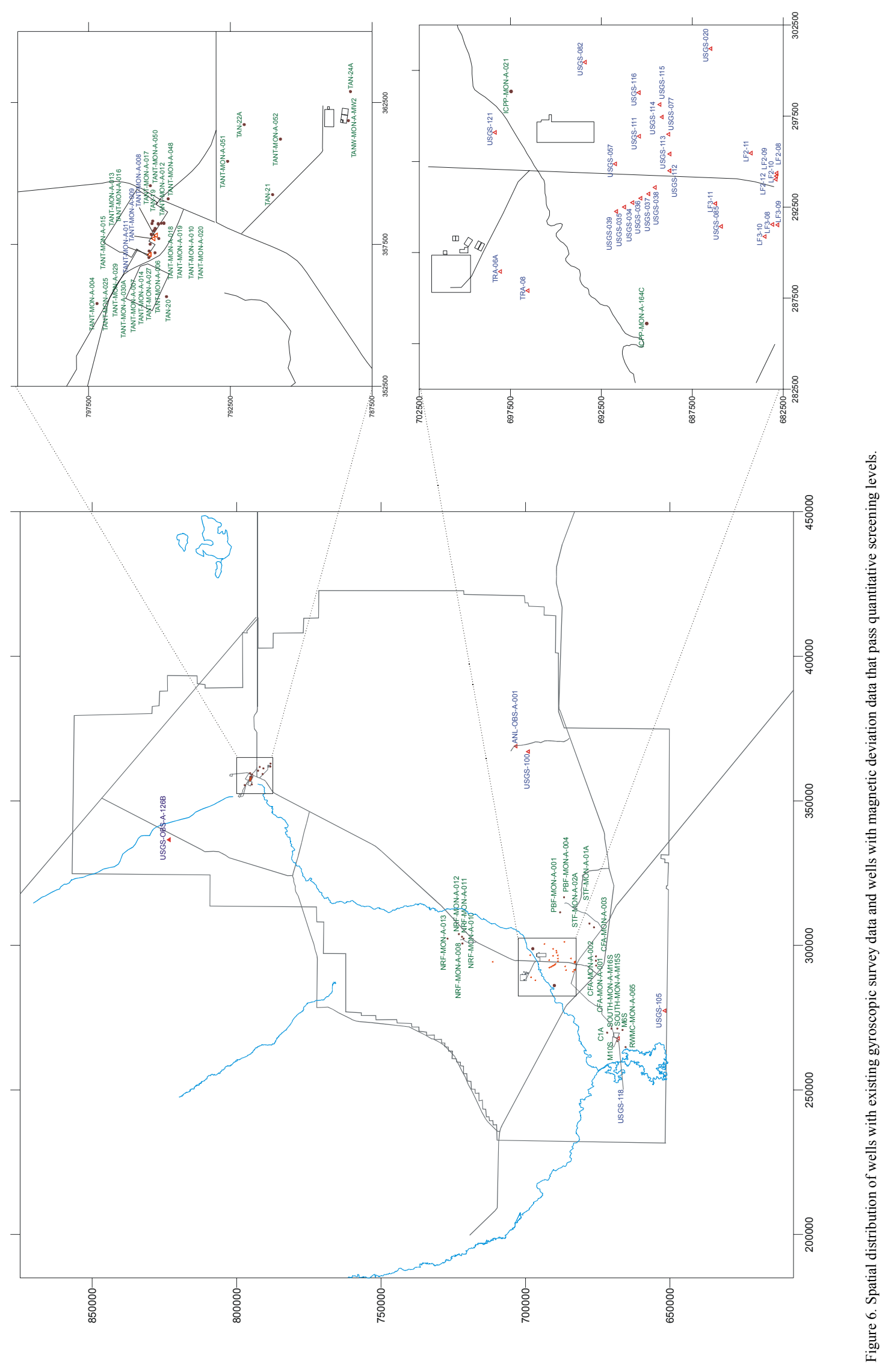




\section{REFERENCES}

Ackerman, D. J., USGS, personal communication, March 2001.

Anderson, S. R., M. A. Kuntz, L. C. Davis, Geologic Controls of Hydraulic Conductivity in the Snake River Plain Aquifer at and near the Idaho National Engineering and Environmental Laboratory, Idaho, DOE/ID-22155, February 1999.

Arnett, R. C., Brower, J. M., Freiburger, L. M., Level C Validation and Limitations of Historical Groundwater Level Measurements Made at the Idaho National Engineering Laboratory From 1958 to 1992, EGG-ERD-10470, 1993.

Century Geophysical Corporation, on-line help files for 9055 neutron-logging tool, www.century-geo.com, visited March 2001.

Driscoll, F. G., Groundwater and Wells, second edition, Johnson Filtration Systems Inc., St. Paul, Minnesota, 1987.

Helm-Clark, C., Idaho State University faculty, personal communication, March 2001.

Lindholm, G. F., Summary of the Snake River Plain Regional Aquifer-System Analysis in Idaho and Eastern Oregon, USGS Professional Paper 1408-A, 1996.

Peterson, B. R., Practical Use and Application of Geophysical Logs for Hydrological and Environmental Projects, Century Geophysical Corporation, Tulsa, undated.

Wylie, A. H., Gyroscopic Directional Survey of Central Facilities Area Ground Water Wells, Engineering Design File ER-WAG4-31, 1993.

Wylie, A. H. and Hubbell, J. M., Gyroscopic Directional Survey of Central Facilities Area Ground Water Wells, Part II, Engineering Design File ER-WAG4-32, 1993.

Wylie, A. H., Borehole Deviation Survey of Radioactive Waste Management Complex Ground Water Wells, EDF INEL-96/155, Draft, 1996. 


\section{Appendix A}

\section{Principal Information for 337 Aquifer Wells Initially}

Considered for Planned Gyroscopic Logging 
A-2 


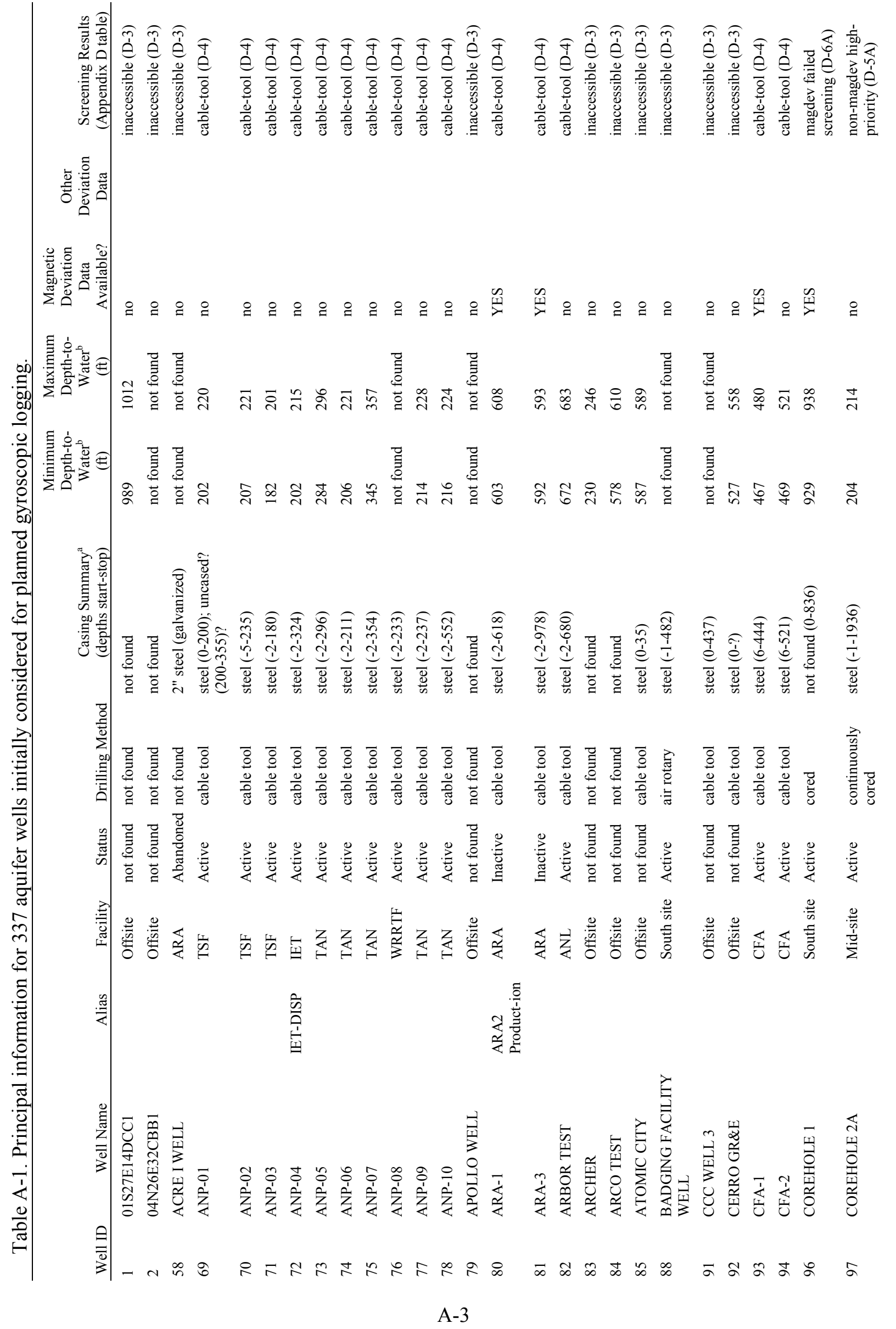




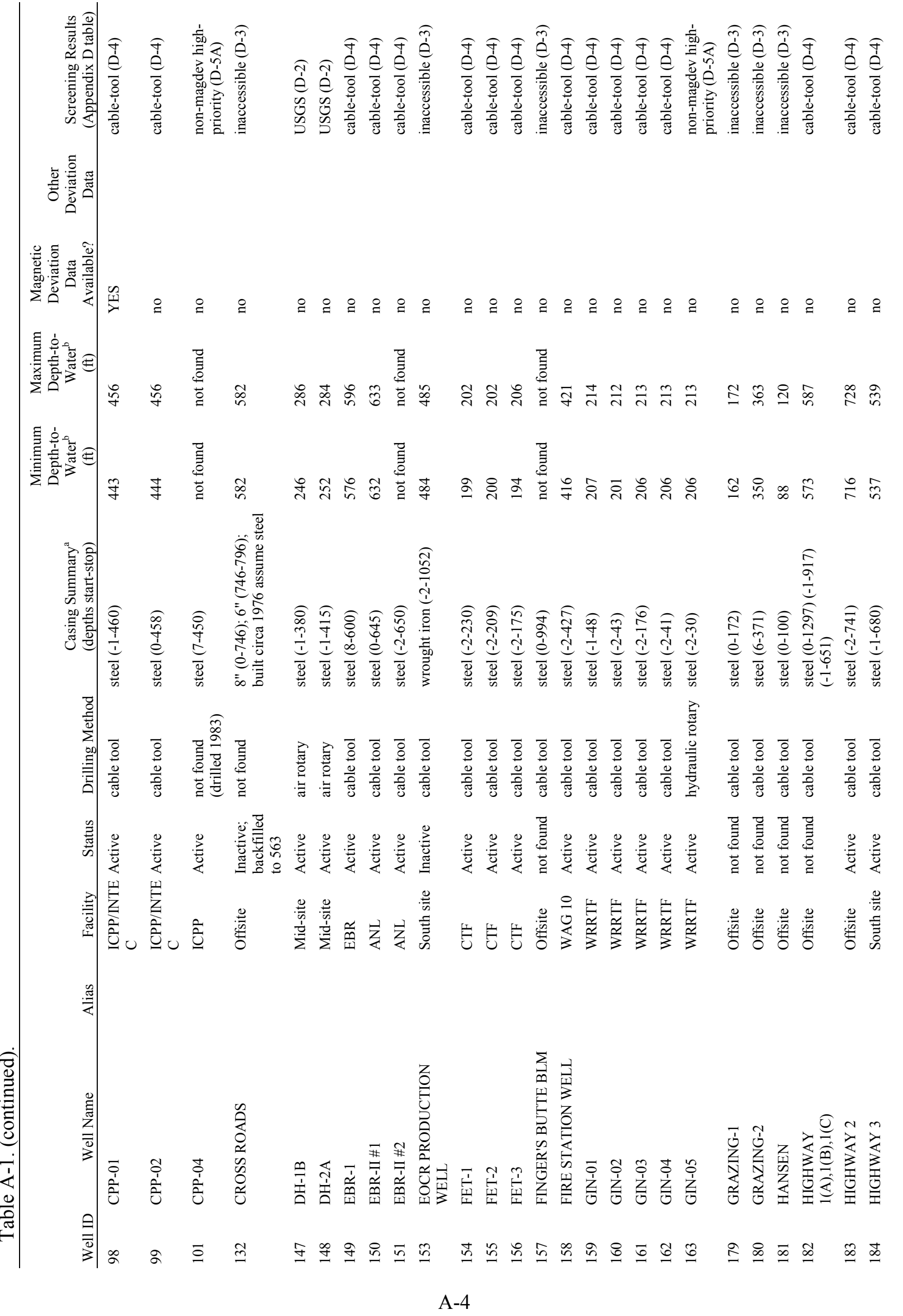




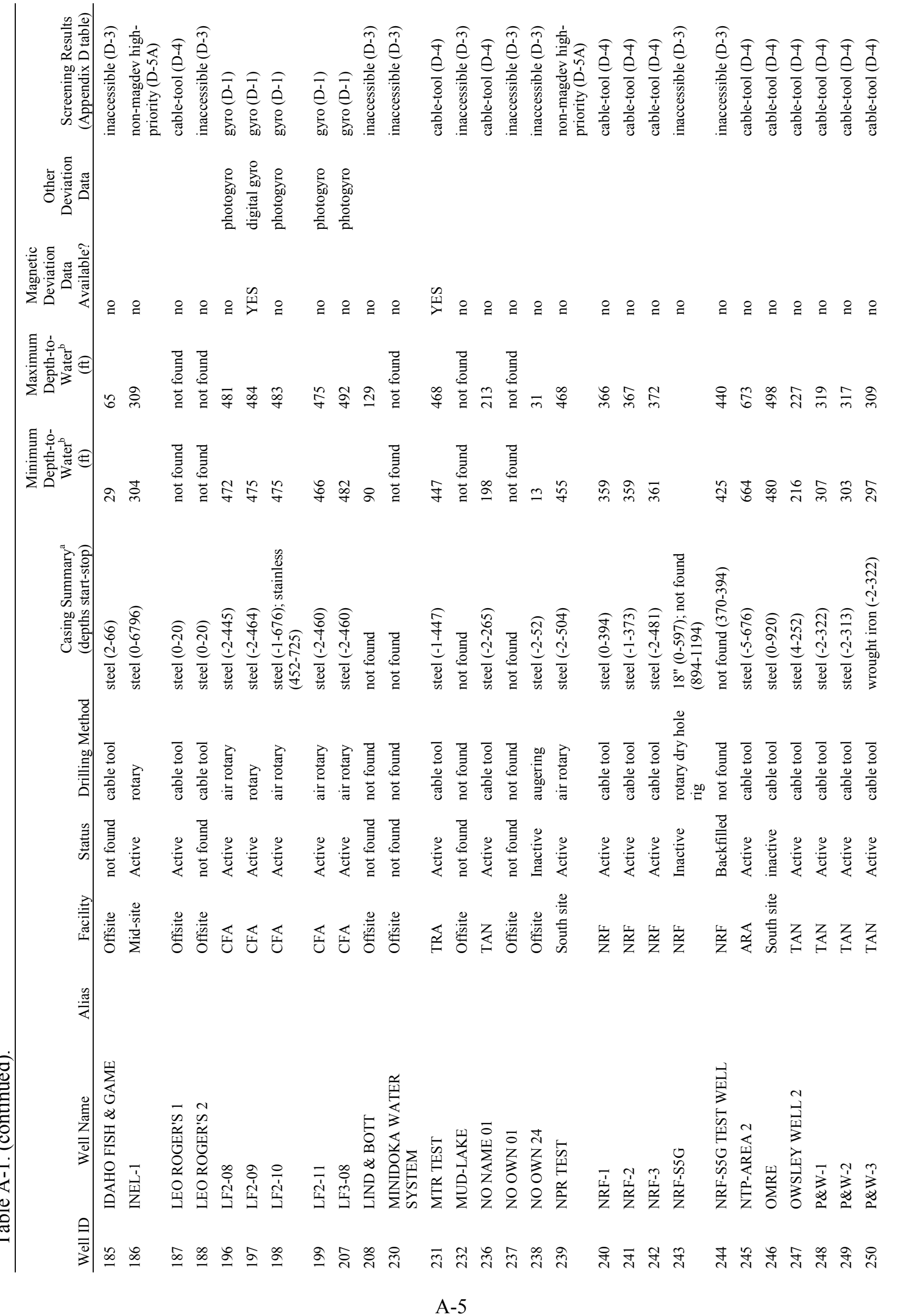




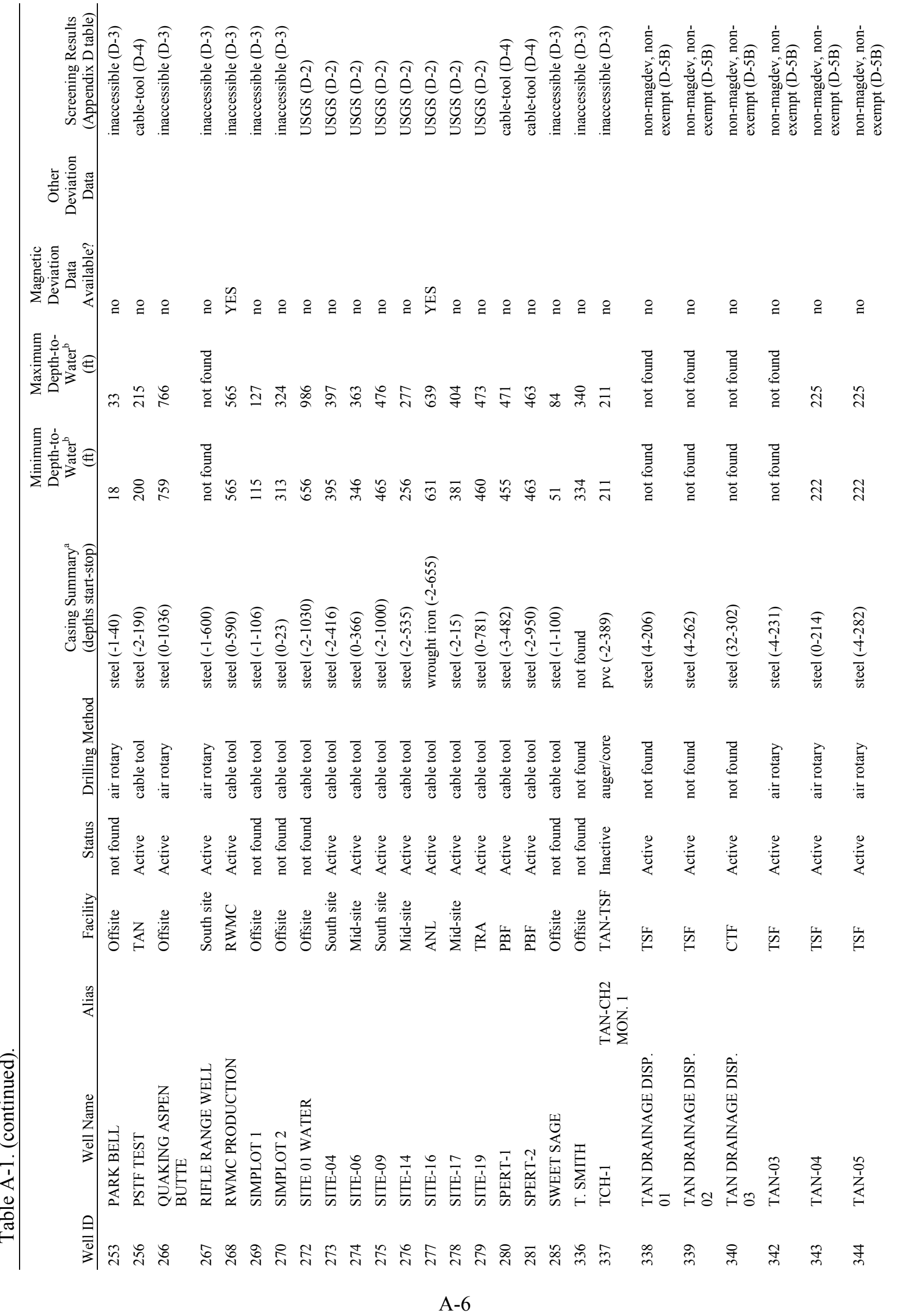




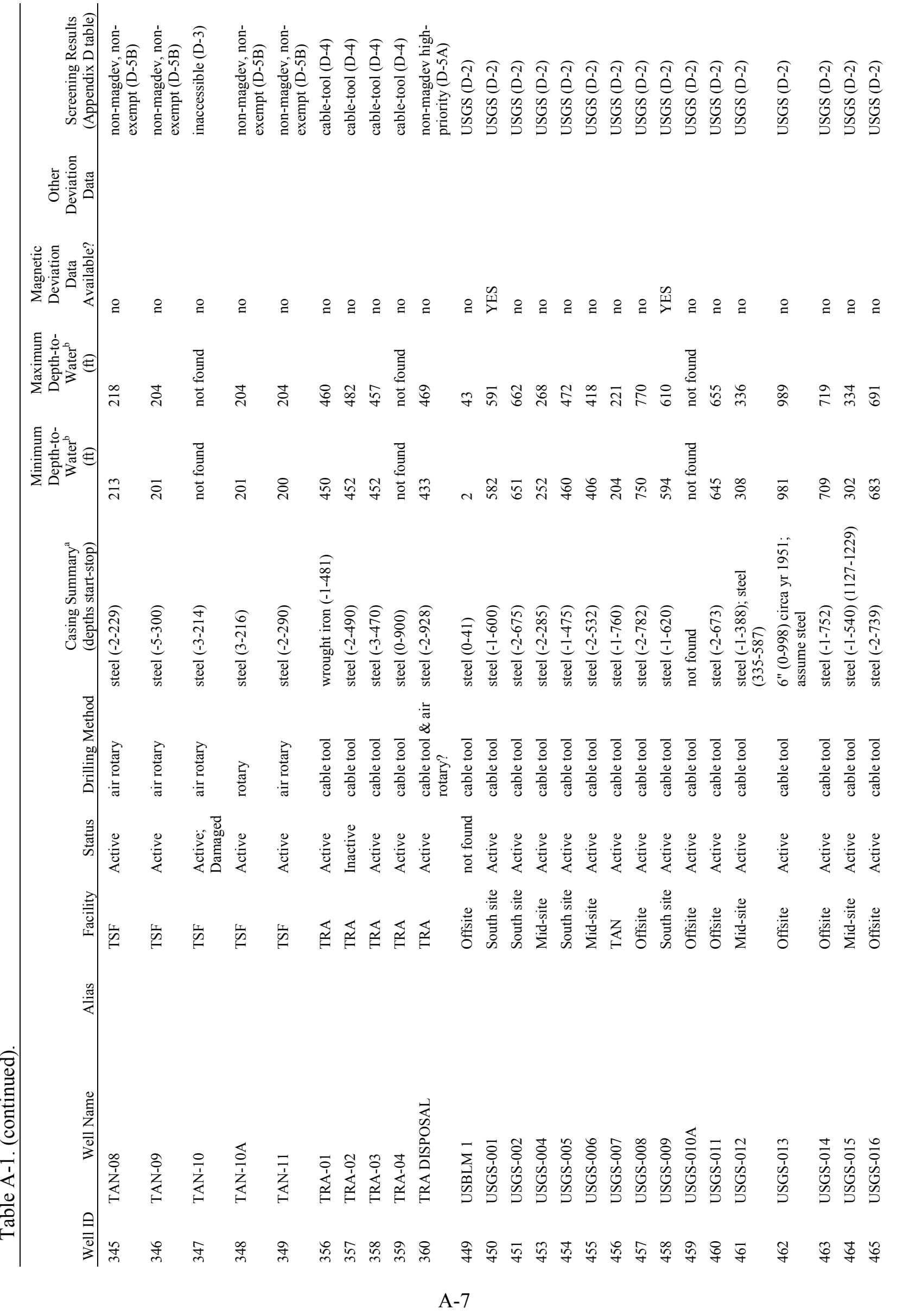




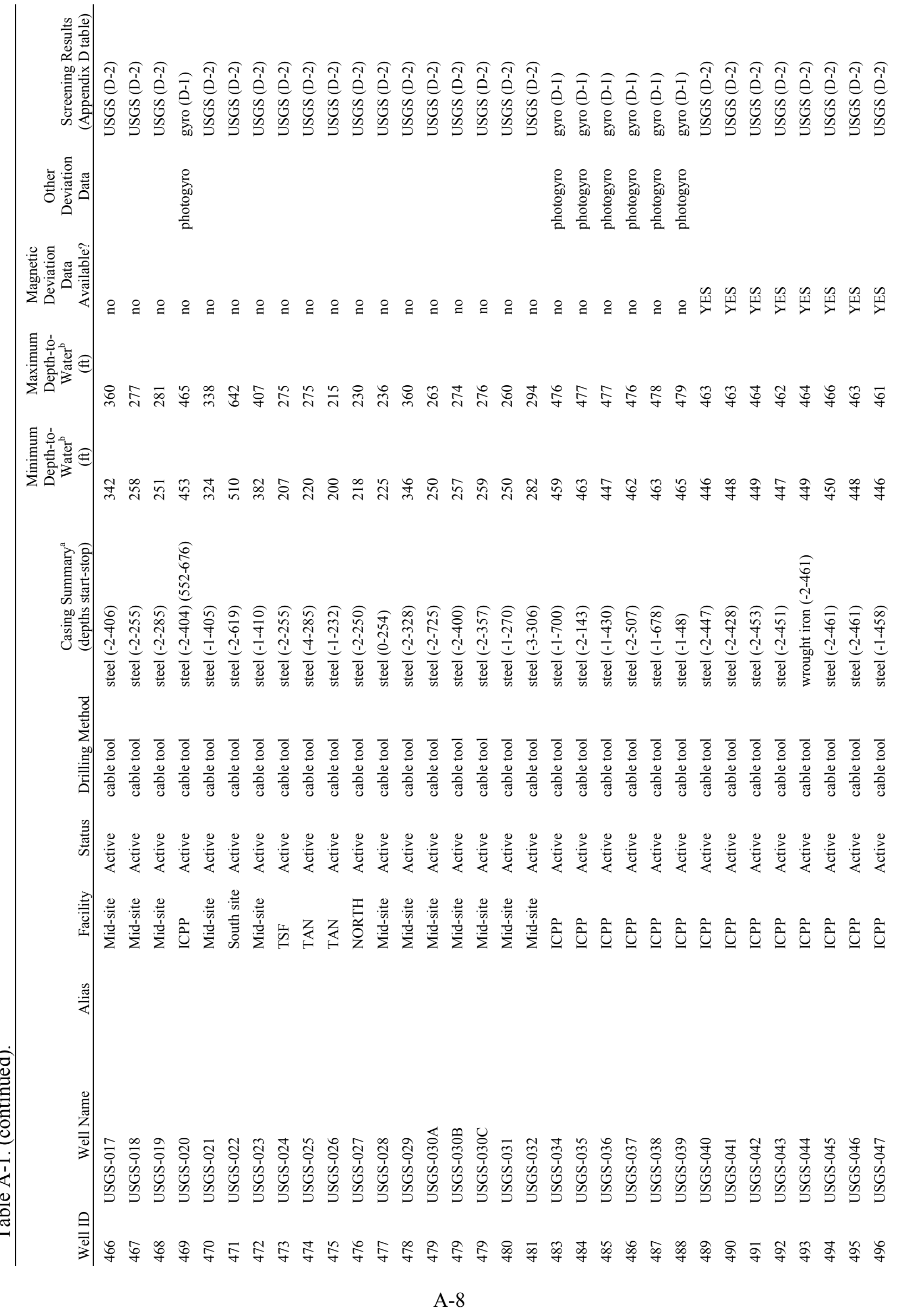




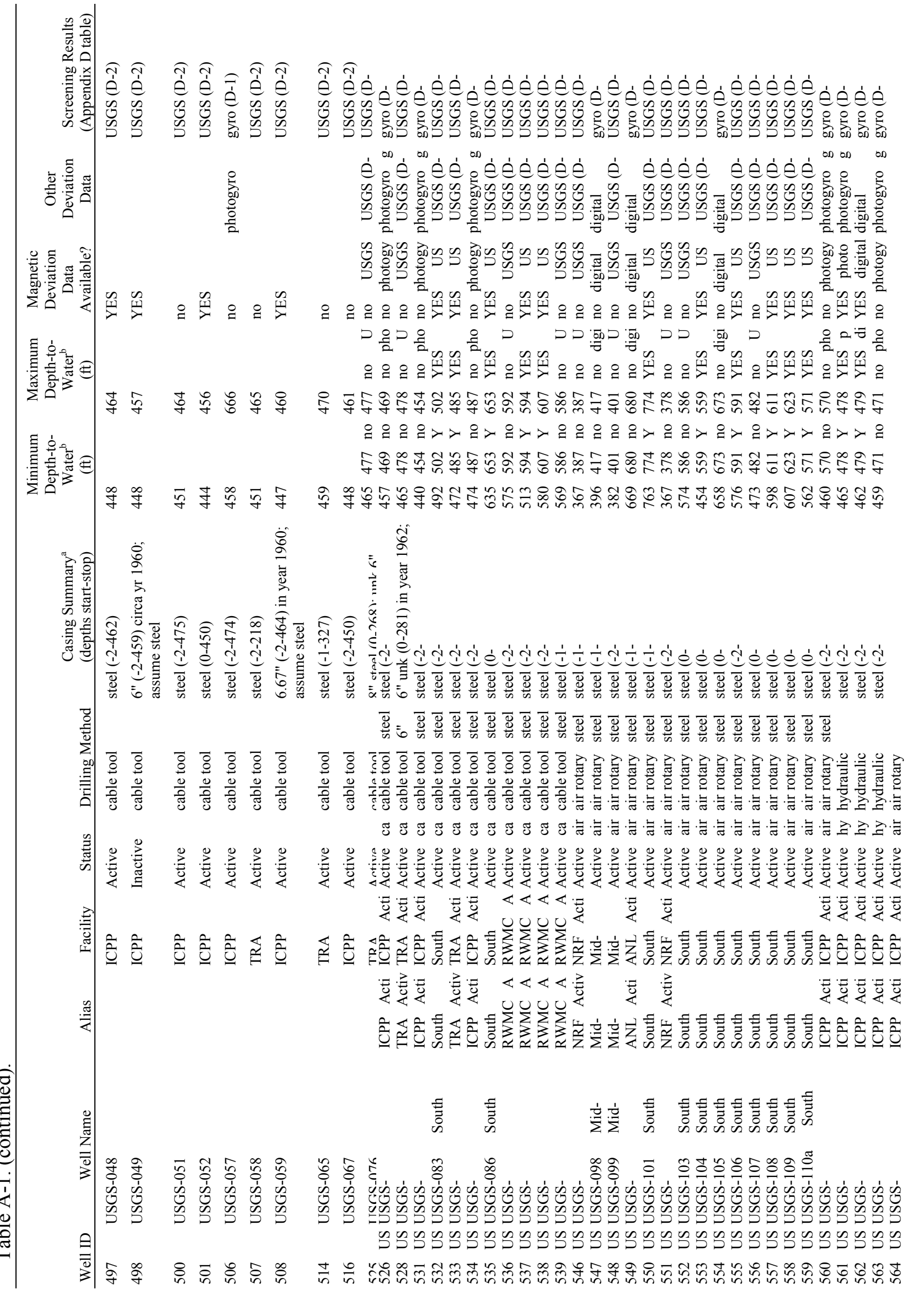

